\title{
THE NATURE OF THE 'GIN’:
}

\section{A NOTE ON 'WHIRLWINDS IN THE PLAIN'}

\author{
B.J. Dalton
}

Miss E.M. Webster's Whirlwinds in the plain appeared in 1980 to great critica acclaim. It is the most important work on Leichhardt to appear since Dr M. Aurousseal's magisterial edition of Leichhardt's Letters. ${ }^{1}$ The author made thorough and scholarly us of an extraordinarily wide range of sources, and unquestionably achieved one of her prine objectives: to demonstrate that A.H. Chisholm's Strange new world ${ }^{2}$ utilised Gilbert's liary - which Chisholm himself discovered in 1937 - in order to denigrate Leichhardt uniustifiably. At the same time she seems to fall into a similar error: to seek in every apparert discrepancy between Gilbert's diary and Leichhardt's Journal an opportunity to denigrae Gilbert and exult Leichhardt. In the instance examined in these pages she has been led into making a completely false inference from the evidence.

After citing a succession of small incidents in order to demonstrate that Gilbert's diary sometimes records events selectively, so as to appropriate unmerited creat to himself, Miss Webster goes on:

Anyone who has observed human nature will be familiar with conparable situations. Another situation, perhaps less familiar to modern readers, occurred when Gilbert was in charge of the camp during Leichhardt's absence. On 18 January 1845 Gilbert noted with humorous appreciation the 'slyness' with which a native offered the explorers the use of women, and two dayslater, as John Murphy reveals, the travellers 'had some gin'. Whatever the natuie of the gin the party enjoyed under Gilbert's auspices, the incident was not one he wished to submit to future readers. ${ }^{3}$

A few pages later the same incident is made to serve a somewhat different purpose: to illustrate Gilbert's 'characteristic inconsistency' of attitude towards Aborigines, of whom, she claims, he had earlier shown himself fearful:

His fears in abeyance, Gilbert characteristically swung to the other extreme. Less than a month after these alarms he was hobnobbing with a native who wanted to know if they were 'desirous of one of his women'. Leichhardt being absent, the acquaintance ripened quickly and two days later the explorers had some gin'.

Brian Dalton is Professor of History and Head of Department at James Cook University. This paper is a by-product of a study of the North Queensland section of Leichhardt's first expedition of 1844-1845 in which intensive use is made of field-work.

1 Aurousseau 1967-68.

2 1953; first published in 1941 as Strange joumey.

3 Webster 1980:3.

4 Webster 1980:391. 
There is an interesting difference between these two versions of the same event. In the first the author leaves little room for doubt about her own view of "the nature of the gin the travellers enjoyed', but tacitly admits that it is not a matter for dogmatic assurance. In the second this reticence has vanished; though oblique, the assertion is plain: on 20 January 1845 'the explorers' had sexual intercourse with one or more Aboriginal women in pursuance of the offer made on the 18th.

The whole of the evidence now surviving about this incident is to be found in five documents, all held in the Mitchell Library, Sydney. Of the five, three only are strictly contemporary unedited manuscripts. A diary kept by John Murphy, the youngest of Leichhardt's party, contains the clue that led to the uncovering of an apparently well-hidden secret. John Gilbert's diary is fuller and more interesting, both generally and on the incident under review. The field notebook in which Ludwig Leichhardt made his daily record of progress in the form of annotated sketch maps, contains one point of significant corroboration, even though Leichhardt was absent from camp at the material time. The other two documents are narratives written up in the form of diaries after the journey was completed, and based partly upon records kept during the expedition which have not survived. Leichhardt's manuscript journal is always to be preferred to the version published in 1847 , which was edited, at times quite heavily, by P.P. King. A manuscript journal by William Phillips, compiled in its present form an unknown number of years after the expedition, is more suspect than any of the others; but used with caution it is not without value. From these five documents it is possible to piece together a coherent and fairly detailed narrative of the five days relevant to the matter.

On 16 January Leichhardt's party was camped on the Mackenzie River, which they had joined a few days earlier. Having found by reconnaissance the previous day that the river maintained a general course to the north-east, well away from their intended track, Leichhardt decided to kill one of the bullocks and leave the other Europeans to convert its meat into sun-dried strips - charqui - while he reconnoitred the country to the north-west.

Just at the moment we were preparing to shoot the bullock, [Leichhardt writes] we heard the cooee of a native, and in a short time two men were seen approaching and apparently desirous of having a parley. Accordingly I went up to them ...

After describing their physical appearance Leichhardt goes on:

They spoke a language entirely different from that of the Darling Downs, but 'yarrai' still meant water. Charley, who conversed with them for some time, told me that they had informed him, as well as he could understand, that the Mackenzie flowed to the north-east. Brown found an empty seed-vessel of the Nelumbrium, in their camp.

The bullock was killed at sunset and the task of converting it into charqui continued all through the next day. On the 18th Leichhardt rode off for his reconnaissance with the two Aborigines of the party, Charley and Brown, leaving the five other Europeans to finish preserving the beef. In the afternoon Charley returned to guide them to the site Leichhardt had selected for the next camp; the leader meanwhile continued his reconnaissance to the north-west with Brown, getting bushed for several days. They did not rejoin the others until 23 January.

Towards dusk on 18 January there was a second visit by Aborigines. Gilbert writes: In the evening we were again visited by the Natives[.] I and Roper with Charlie went out to meet them, as they approached with the emblem of friendship a 
green bough I plucked one from a shrub and did the same [.A]s is usual among them the party sat down together while one stepped forward towards us and entered into a conversation. Of course we could not understand a word ke said but from his gestures it seemed he was very anxious to know why we came here, and whither we were going. Charlie made out a few words only not sufficient to gain any positive information. The Native seemed a very good tempered fellow, and was very anxious at parting to know if we were desirous of one of his women. Charlie understood him perhaps better than we but there was a certain slyness and half laugh about the fellow that could not well be mistaken by us who knew not a word that he uttered, we parted for the night very good friends, one of the old women however seemed as if very dissatisfied [-] whether with us particularly or not we could not tell[. A] $\mathrm{t}$ night we had a thunderstorm and a little rain...

In Murphy's briefer account, which makes no mention of the offer, he remarks:

... . the poor old gin cried very much and seemed very sorry we had come so far and wished us to go away. I gave the native an acidulated drop which he did not eat but took care of $[. T]$ hen they returned down the river. [A] $t$ night a thunderstorm.

Phillips disposes of the visit still more summarily. He estimated the number of visitors at about eight, which agrees reasonably with Gilbert's note that there were five men and four or five women and children. Together the estimates suggest that the visitors comprised the whole of a 'band'. The one additional point made by Phillips is that the visitors made 'presents of their Spears, Waddies, Beads etc. to the two Natives who accompanied our Party'.

In this second meeting with the same band of Aborigines, Gilbert behaved exactly as Leichhardt had in the first: going out from the camp to meet the Aborigines when it was clear they wanted a parley and using Charley as interpreter to glean what information he could. If Gilbert was 'hobnobbing' on the 18th, so was Leichhardt on the 16th. As for the offer of sexual services, there was nothing novel about it. Many other explorers reported, and probably most received, similar offers. ${ }^{5}$ Gilbert had recorded an earlier one on 30 October 1844; Leichhardt himself notes two subsequent instances, on 21 September and 2 December 1845, without incurring Miss Webster's censure. Her second account of the offer of 18 January implies that it was made in the course of the meeting: her sole source is explicit in stating that it came 'at parting'. Gilbert's reference to the Aborigine's 'slyness' is purely factual, made in order to explain why 'the fellow could not well be mistaken' though the Europeans understood not a word and Charley hardly more. At the time it was made, the offer might have aroused in Gilbert any emotion from lust at one extreme to disgust at the other, for all we know. His narrative, the only source we have, expresses no emotion whatever: 'humorous appreciation' is Webster's own gloss upon the evidence.

The intention had been to shift camp on 19 January to the new site Leichhardt had selected, but the dried meat, covered against rain overnight, was found to have sweated and had to be set out to dry again. Murphy makes it clear that another visit from the Aborigines was expected, but he agrees with Gilbert and Phillips in stating that it did not take place. On 20 January the move was made to the new site; none of the records mentions meeting or seeing Aborigines. 


\section{NOTES AND DOCUMENTS}

On coming to camp [Gilbert writes] we had scarcely time to get our tents up before rain came on, as it appeared only at first a slight shower we were rather careless about our precautions but it was soon followed up by Thunderstorms and a regular Tropical rain set in which continued pouring down very heavily for three hours. being on a slope the water soon commenced running down upon us and to avoid being washed out of our tents it was necessary to dig deep trenches round the upper parts to carry off the water. Such a heavy shower and of so long a duration we have not experienced since leaving Blackfellows Camp. ${ }^{6}$ The waterhole in a watercourse when we arrived had not more than a foot in depth of water, the rain increased it to at least 12 feet in depth nearly and a 100 yards in length, had the rains continued 2 hours longer, we should have been under the necessity of moving higher up, to get beyond its reach.

At the beginning of his shorter entry for 20 January John Murphy interpolated the words: 'here we had some gin'. Nothing else in the entry has any overt connection with these words. If Webster has correctly deciphered their meaning, the encounter must have occurred either during the move between camps or at the rain-sodden camp of 20 January. Neither seems a likely setting; but it must be conceded that neither is impossible. To judge whether her interpretation is sound, it is well to look for other clues. No long search is necessary.

During the first four months of the expedition a name was given to virtually every camp. The fullest list is on the sketch maps in Leichhardt's field notebooks, though few are mentioned in his Journal. Gilbert noted some in his diary; Murphy rather more, often closing his day's entry with a brief explanation of the name. Some names refer to natural features: Eel camp (13 November 1844), White Kangaroo camp (5 December 1844), and Coal camp (14 January 1845); others to an anniversary: New Year camp (31 December 1844), Gilbert's birthday (14 March 1845) and Good Friday (21 March 1845); still others to an incident during the day: Speared Horse camp ( 7 December 1844), Roper's strayed camp ( 8 December 1844) and Lost Axe camp (3 January 1845). ${ }^{7}$

The camp of 16-19 January 1845 was called 'Redmonds last' by Leichhardt, and 'Redmans' by Murphy and Gilbert, after the bullock slaughtered there. Leichhardt and Gilbert called the next one 'Spirit camp'. Murphy wrote 'Grog camp' in the margin of his diary for 20 January but for once omitted to explain the name. When he noticed the omission at some later date, there was no room to add anything in his usual spot at the end of the entry for 20 January; accordingly he squeezed in the words 'today we had some gin' at its start. There they stand not three inches from the marginal entry 'Grog camp'.

No room for doubt remains about the incident of 20 January from which the camp derived its name. Drenched by a long tropical downpour, tired from hurried ditch digging to divert the runoff away from the stores and almost certainly unable to kindle a fire, ${ }^{8}$ the explorers had a rare tot of spirits all round. No single point made or implied in the accounts

6 Gilbert refers here to a violent thunderstorm on the night of 22-23 December 1844 which, he noted at the time, was the worst experienced since leaving the Darling Downs.

7 I retain the slightly eccentric capitalisation in Leichhardt's notebook.

8 This was Leichhardt's experience the previous night when caught in a thunderstorm which hardly touched Redmans camp. 
given in Whirlwinds in the plain is substantiated by the evidence: the main point is conclusively refuted by the very document from which it was deduced.

Of course the incident is small, occupying in all a dozen lines in a book of more than 420 pages; but it is not insignificant. A great part of the book comprises instances quite as small, related in the same manner: the purport of documents - themselves meticulously cited in end-notes - is reported crisply, usually with no quotation of sufficient length for the reader to exercise any independent judgement; emotional states are ascribed as if they were as verifiable as dates; incidents are analysed in complete isolation from their contexts - the sequence of events of which they formed part and the physical environment in which they took place.

Miss Webster writes of her bête noire, Strange new world, as 'Depending for its effect upon brief, forceful statements which could only be disputed at length and in tedious detail . . A Although she is incomparably more thorough and scrupulous a scholar of history than Chisholm, the remark has some applicability to her own book.

9 Webster 1980:380.

\section{BIBLIOGRAPHY}

Aurousseau, M. ed. The letters of Ludwig Leichhardt. 3 vols, Cambridge, 1967-68.

Chisholm, A.H. Strange new world. Adelaide, 1953.

Reynolds, Henry. The other side of the frontier. Townsville, 1981.

Webster, E.M. Whirlwinds in the plain: Ludwig Leichhardt - friends, foes, and history. Carlton, Vic., 1980.

\section{ABORIGINES AND TORRES STRAIT ISLANDERS}

\section{IN THE SECOND WORLD WAR}

The Strategic and Defence Studies Centre has recently published a Working Paper, no. 121, Aborigines and Torres Strait Islanders in the Second World War by Rober.t A. Hall, which describes the rarely acknowledged contribution made by Aborigines and Torres Strait Islanders as enlisted men, as de facto servicemen and in various civilian support areas. The paper also discusses the contradictory Service attitudes towards these people, and outlines their Service conditions. It costs $\$ 2.50$ and may be ordered from:

Publications Officer

Strategic and Defence Studies Centre

Research School of Pacific Studies

Australian National University

G.P.O. Box 4, Canberra A.C.T. 2601. 